\title{
İnce Cidarlı Kompozit Kiriş Olarak Modellenmiş Uçak Kanatlarının Eğilme-Eğilme Bağlaşım Titreşiminin Aktif Kontrolü
}

\author{
Kaan Y1ld1z ${ }^{1^{*}}$ \\ ${ }^{1}$ İstanbul Teknik Üniversitesi, Uçak ve Uzay Bilimleri Fakültesi, Uçak Mühendisliği Bölümü, İstanbul, Türkiye (ORCID: 0000-0002-2670-8619)
}

(İlk Geliş Tarihi 1 Aralık 2019 ve Kabul Tarihi 31 Aralık 2019)

(DOI: $10.31590 /$ ejosat.659331)

ATIF/REFERENCE: Yıldız, K. (2019). İnce Cidarlı Kompozit Kiriş Olarak Modellenmiş Uçak Kanatlarının Eğilme-Eğilme Bağlaşım Titreşiminin Aktif Kontrolü. Avrupa Bilim ve Teknoloji Dergisi, (17), 1274-1284.

$\ddot{O} z$

Aktif titreşim kontrol metotlarının geliştirilmesi ve uygulanması günümüzde hava uzay yapılarının performans gerekliliklerini sağlamak ve verimliliklerini iyileştirmek açısından oldukça önemli bir konu haline gelmiştir. Bu ilginin en büyük sebebi bu tarz malzemelerin havacılık ve uzay, otomotiv, helikopter ve turbo makinelerin palleri ve robot kolları gibi çeşitli farklı yapılara kolayca uyarlanabilmesi ve kullanılabilir durumda olmasından kaynaklanmaktadır. Akıllı veya uyarlanabilir malzemelerin kullanımı ile, yapıların dinamik karakteristiklerinin öngörülebilir bir şekilde kontrol edilmesi mümkündür. Buna ek olarak, yapısal rezonans ya da çırpınma gibi dinamik kararsızlıkların da önüne geçilebilir. Yapılmış olan bu çalışmada, elmas kesitli uyarlanabilir bir uçak kanadının piezoelektrik malzemeler yardımıyla aktif titreşim kontrolü incelenmiştir. Uçak kanadı ince cidarlı bir kompozit kiriş olarak modellenmiş ve piezoeyleyiciler ve algılayıcılar yapının içine çift olarak çalışmaları için gömülmüştür. Gömülmüş olan bu piezoelektrik malzemeler, tüm kiriş boyunca uzanmaktadırlar ve bu sayede sınır moment kontrol yöntemini geçerli kılmışlardır. Kapalı devre aktif titreşim kontrolü kayma etkilerinin de dahil olduğu enine ve yanal eğilme bağlaşımı gösteren uçak kanadına uygulanmıştır. Oransal geri besleme ve hız geri besleme kontrol yasaları olmak üzere iki farklı kontrol yasası kullanılmıştır. Serbest titreşim problemi Extended Galerkin Yöntemi ile çözülmüş, çeşitli geometrik ve malzeme ile alakalı kalınlık oranı, açıklık oranı ve elyaf açıları gibi parametrelerin doğal frekanslar üzerindeki etkisi incelenmiştir. Elde edilen sonuçlar ışığında, parametrelerin değişimi ile birlikte kompozit uçak kanatlarının tasarımı için bilgiler elde edilmiştir. Hız geri besleme yasası, oransal geri besleme yasasına göre doğal frekanslar üzerinde daha fazla kontrol sağlaması nedeniyle daha elverişli bulunmuştur. Ayrıca hız geri besleme yasası sisteme suni yapısal sönümleme katı̆ğından dolayı hava uzay yapılarında dinamik ya da aeroelastik kararsızlıklar doğurabilecek tehlikeleri engelleme potansiyeline sahiptir.

Anahtar Kelimeler: ince-cidarlı kompozit kirişler, uyarlanabilir kanatlar, aktif kontrol metotları, oransal geri besleme kontrol yasası, hız geri besleme kontrol yasası.

\section{Active Control of Bending-Bending Coupled Vibration of Aircraft Wings Modeled as Thin-Walled Composite Beams}

\begin{abstract}
The development and implementation of active vibration control methods have attracted considerable attention in the recent years due to enhanced efficiency and performance requirements in aerospace structures. Using adaptive materials, the dynamic characteristics of structures could be controlled in a predictable manner to prevent dynamic instabilities such as structural resonance. This study presents the active vibration control of a diamond-shaped adaptive aircraft wing by using piezoelectric actuation. The aircraft wing is modeled as a thin-walled composite beam in which the piezoactuator/sensors are embedded into the structure to serve as couples. The piezoactuators/sensor are spread over the entire span to benefit from the bending moment control. The closed loop active vibration
\end{abstract}

\footnotetext{
* Sorumlu Yazar: İstanbul Teknik Üniversitesi, Uçak ve Uzay Bilimleri Fakültesi, Uçak Mühendisliği Bölümü, İstanbul, Türkiye, ORCID: 0000-00022670-8619, yildizkaa@gmail.com
} 
control is performed for the aircraft wing featuring the coupled motion of transverse and lateral bending including shear effects. Two different control laws, namely proportional feedback control law and velocity feedback control law are employed. The free vibration problem is solved by the Extended Galerkin Method (EGM) and the effects of several geometrical and material aspects such as thickness and aspect ratios, and ply angle on the natural frequencies are investigated. The obtained results with the variations of such parameters provide guidelines for the design of thin-walled composite aircraft wings. Through comparison the velocity feedback control law is found to be superior to the proportional feedback control law as it provides better controllability of natural frequencies. Furthermore, the velocity feedback law also introduces artifical structural damping, hence providing a capability of suppressing the oscillations which may cause dynamic/aeroelastic instabilities in aerospace structures.

Keywords: thin-walled composite beams, adaptive wings, active control methods, proportional feedback control law, velocity feedback law.

\section{Giriş}

Aktif geri besleme kontrol metodlarının geliştirilmesi ve uygulanması, son yıllarda gelişmiş havacılık yapılarına yönelik artan verimlilik ve performans ihtiyaçları nedeniyle büyük dikkat çekmiştir. Bu gelişme, temel olarak yapıda ciddi arızaya neden olabilecek dinamik kararsızlıkları önlerken iyileşen titreşim davranışından ve harici yüklere karşı verilen geliştirilmiş dinamik yanıttan kaynaklanmaktadır. Dinamik davranışı kontrol etmenin olası bir yolu uyarlanabilir gömülü malzemelerin kullanılmasıdır. Bu "uyarlanabilir" yapılar, harici yüklere karşılık verilen dinamik yanıtı iyileştirilirken, yapısal rezonansın, dinamik/aeroelastik kararsızlıkların önlenmesi gibi gereklilikleri yerine getirmek için de kullanılabilir.

Yapıların aktif kontrolü, ilk kez Bailey ve Hubbard (1985) tarafından piezoelektrik eyleyiciler kullanılarak tanıtılmıştır. Bu çalışmayı takiben, eyleyicilerin mekanik modellemesi Crawley ve De Luis (1987) tarafindan geliştirilmiş ve gömülü eyleyicilere ve algılayıcılara ilişkin başka birçok teori Wang ve Rogers (1991), Ghosh ve Batra (1995), Mitchell ve Reddy (1995), ve Han ve arkadaşları (1997) tarafından geliştirilmiştir. Aktif kontrol teknikleri arasından, hava-uzay yapıları için sıkça uygulanan bir teknik olan piezoelektrik kabuklar ile sınır moment kontrolü ilk kez Tzou (1993) tarafından sunulmuştur. Özellikle Na (1997), Qin (2001), Song ve arkadaşları (2001) herhangi bir şeklin açık kesit veya kapalı kesit kirişleri için uygun olan ince cidarlı kompozit kiriş teorisinin birleşimi ile, gelişmiş hava aracı yapılarının titreşim kontrolü üzerine uyarlanabilen malzeme teknolojisini sunmuştur. Son dönemde, ince cidarlı kompozit yapıların gelişmiş hava-uzay yapılarının tasarımında kullanılmasının potansiyel avantajı dolayısıyla bu alanda sayısız gayret gösterilmiştir (Librescu vd., 1993; Librescu vd., 1996; Meirovitch, 1997). Sınır moment geri besleme kontrolünün yanısıra, piezoelektrik eyleyiciler/algılayıcılar kiriş üzerinde belirli bir konuma yama olarak yerleştirilerek kullanılmıştır ve bu konumlarından kaynaklanan etkileri ve verimleri incelenmiştir ( $\mathrm{Na}$ ve Librescu, 1998, 2000a, 2000b). Ek olarak, piezo katmanlar/yamalar ile ideal kontrol gibi daha gelişmiş kontrol sistemleri yapılara uygulanmıştır (Librescu, 1997; Na ve Librescu, 1998, 2000a; Yildiz vd., 2014).

Yukarıda bahsedilen çalışmalar genel olarak, zamana bağlı harici yüklere karşılık verilen dinamik yanıtın özelliklerini kontrol etmek salınımları sönümlemek ve yapıda meydana gelebilecek dinamik kararsızlıkların ortaya çıkmasını önlemek için uyarlanabilir yapıların kullanımının azımsanmayacak bir potansiyele sahip olduğunu göstermiştir. Bununla birlikte, yapının titreşim davranışını etkileyen tüm hususlar, ayrıca kontrol özellikleriyle de ilişkilidir ve bu ilişki dikkatli bir şekilde ele alınmalıdır. Yapılan bu çalışmada, uyarlanabilir bir kompozit uçak kanadının titreşiminin incelenmesi, geometrik özellikler de dikkate alarak ele alınarak hedeflenmiştir. Kanat yapısı elmas şeklinde kesit alana sahip ince cidarlı bir kompozit kiriş olarak modellenmiştir.

Anti-simetrik bir kompozit yerleşim düzeni ele alınmış ve yapının düşey eğilme-yanal eğilme-enine kayma-yanal kayma hareketi incelenmiştir. Aktif titreşim kontrolü, gömülü piezoelektrik eyleyiciler ve algılayıcılar kullanılarak kanadın uç kısmında üretilen sınır momenti ile sağlanmıştır. Uyarlanabilir kompozit kirişin dinamik özellikleri, açıklık oranı, kalınlık oranı ve elyaf açısı gibi geometrik ve malzemeye bağlı parametrelerin değiştirilmesi ile incelenmiştir. Genel sonuçlar doğal frekansların uygulanan geri besleme kazancının varlığında artma eğiliminde olduğunu ve hız geri besleme kontrol yasasının oransal geri besleme yasasından daha hassas ve etkili olduğunu göstermiştir. Ayrıca, hız geri besleme kontrolü için maksimum sönümleme faktörü uygulanan geri besleme kazancında belirli bir değere ulaşmakta ve ardından artan kazanç ile aniden azalmaktadır.

\section{Aktif Titreşim Kontrolü}

İnce cidarlı kompozit kirişlerin aktif titreşim kontrolü iki farklı yöntemle sağlanabilmektedir. Bu yöntemlerden ilki piezoelektrik malzemeleri kiriş üzerine yama olarak yerleştirirken, diğeri piezoelektrik malzemelerin bütün kiriş boyunca yayılmasını sağlayarak sınır moment kontrolü tanımını ortaya koyar. Yapılan olan bu çalışmada, sınır moment kontrolü ele alınmıştır. Piezoelektrik malzemelerin kiriş boyunca yayılması sonucunda indüklenen sınır moment ifadeleri direkt olarak uygulanan elektrik alanın linear fonksiyonları olarak aşağıdaki şekilde yazılabilirler:

$$
\begin{aligned}
& M_{x}^{a}=\xi_{3} C_{M_{x}} \\
& M_{x}^{a}=\xi_{3} C_{M_{x}}
\end{aligned}
$$


Kiriş boyunca yapılan integrasyon sonucu sınır moment ifadeleri sınır koşullarında belirmektedir (Tzou, 1993; Song vd., 2001). Yapılan bu çalışmada, kapalı devre kontrol sistemleri düşünüldüğümde, iki farklı kontrol yasası ele alınmıştır: oransal geri besleme kontrol yasası, hiz geri besleme kontrol yasası.

Kapalı devre kontrol sistemleri eyleyici ve algılayıcıların bir sisteme aynı ande yerleştirilmesi ile oluşturulmaktadırlar. Algılama özellikleri sayesinde bir geri besleme alınmakta ve buna göre bir yanıt üretilmektedir. Bu kapsamda açık devre kontrol sistemlerine göre büyük avantaja sahiptirler. Algılayıcılar tarafından elde edilen voltaj değerleri uygun kazanç değerleri ile kuvvetlendirilir ve eyleyicilere geri beslenirler. Böylece daha verimli kontrol mekanizmaları oluşturulmaktadır. Kapalı devre kontrol yasaları için detaylı bilgi, ilgili denklem ve ifadeler çeşitli çalışmalarda bulunabilir (Song vd., 2001; Librescu ve Song, 2005).

Oransal geri besleme kontrol yasasında, eyleyicilere gönderilen elektrik alan direkt olarak algılayıcılardan okunan voltaj ile doğru orantılıdır. Bir kiriş örneği düşünüldüğünde, kirişin uç pozisyonu algılanmakta ve bu bilgi kontrol kazancı ile kuvvetlendirildikten sonra eyleyicilere yönlendirilmektedir. Böylece elektrik alan ile kirişin uç pozisyonu arasında aşağıdaki ilişkiler kurulmaktadır (Librescu vd., 1996; Song vd., 2001):

$$
\begin{aligned}
& \xi_{3}^{x}(t)=\frac{K_{p} V_{S}^{x}(t)}{h_{a}} \\
& \xi_{3}^{y}(t)=\frac{K_{p} V_{S}^{y}(t)}{h_{a}}
\end{aligned}
$$

Böylece moment ifadeleri aşağıdaki şekilde yazılabilir:

$$
\begin{aligned}
& M_{x}^{a}=-\frac{K_{p} C_{M_{x}^{a}}}{h_{a}}\left[C_{x}^{S} \theta_{x}(L, t)\right]=-K_{p} C_{11} \theta_{x}(L, t) \\
& M_{y}^{a}=-\frac{K_{p} C_{M_{y}^{a}}}{h_{a}}\left[C_{y}^{S} \theta_{y}(L, t)\right]=-K_{p} C_{22} \theta_{y}(L, t)
\end{aligned}
$$

Diğer taraftan, hız geri besleme kontrol yasasında ise, piezoelektrik malzemelerce indüklenmiş momentler ile kirişin ucunun sahip olduğu hız arasında bir orantı bulunmaktadır. Kirişin ucundaki hız bilgisi algılayıcılar tarafından tespit edilmekte ve kontrol kazancı ile kuvvetlendirildikten sonra eyleyicilere gönderilmektedir. Dolayısıyla, kirişin uç pozisyonunun zamana göre türevi ile uygulanan elektrik alan arasında bir ilişkiden söz edilmektedir (Librescu vd., 1996; Song vd., 2001):

$$
\begin{aligned}
& \xi_{3}^{x}(t)=\frac{K_{v} d V_{S}^{x}(t) / d t}{h_{a}} \\
& \xi_{3}^{y}(t)=\frac{K_{v} d V_{S}^{y}(t) / d t}{h_{a}}
\end{aligned}
$$

Böylece moment ifadeleri aşağıdaki hale gelmektedirler:

$$
\begin{aligned}
& M_{x}^{a}=-\frac{K_{v} C_{M_{x}^{a}}}{h_{a}}\left[C_{x}^{S} \dot{\theta}_{x}(L, t)\right]=-K_{v} C_{11} \dot{\theta}_{x}(L, t) \\
& M_{y}^{a}=-\frac{K_{v} C_{M_{y}^{a}}}{h_{a}}\left[C_{y}^{S} \dot{\theta}_{y}(L, t)\right]=-K_{v} C_{22} \dot{\theta}_{y}(L, t)
\end{aligned}
$$

Yukarıdaki denklemlerde $h_{a}$ piezoelektrik malzemenin kalınlığını ifade etmektedir, $K_{P}$ ve $K_{V}$ değerleri ise oransal geri besleme kazancı ile hız geri besleme kazancını belirtmektedir. Moment ifadelerinin daha detaylı çıkarımları Librescu ve Song tarafından yayınlanmış olan kitapta (Librescu ve Song, 2005) bulunmaktadır.

\section{Hareket Denklemleri}


Yapılan bu çalışmada anti-simetrik konfigürasyona sahip ince cidarlı kompozit kirişler ele alınmıştır. Anti-simetrik konfigürasyon literatürde aynı zamanda Çevresel Tekdüze Katıllk (Circumferentially Uniform Stiffness) olarak da bilinmektedir. Bu kompozit yerleştirme konfigürasyonuna sahip olan ince cidarlı kirişler birbirinden bağımsız olan iki tür bağlaşım göstermektir. Bunlar sırasıyla eksenel uzama-burulma ve düşey eğilme-yanal eğilme-enine kayma-yanal kayma bağlaşımlarıdır. Yapılan bu çalışmada ikinci bağlaşım türü detaylı olarak ele alınmıştır. Bu bağlaşımı tanımlayan hareket denklemleri Librescu ve Song (2005) tarafından aşağıdaki şekilde elde edilmiştir:

$$
\begin{gathered}
\delta u_{0}: a_{34} \theta_{x}^{\prime \prime}+a_{44}\left(u_{0}^{\prime \prime}+\theta_{y}^{\prime}\right)-b_{1} \ddot{u}_{0}=0 \\
\delta v_{0}: a_{25} \theta_{y}^{\prime \prime}+a_{55}\left(v_{0}^{\prime \prime}+\theta_{x}^{\prime}\right)-b_{1} \ddot{v}_{0}=0 \\
\delta \theta_{x}: a_{33} \theta_{x}^{\prime \prime}+a_{34}\left(u_{0}^{\prime \prime}+\theta_{y}^{\prime}\right)-a_{55}\left(v_{0}^{\prime}+\theta_{x}\right)-a_{25} \theta_{y}^{\prime}-\left(b_{4}+b_{14}\right) \ddot{\theta}_{x}=0 \\
\delta \theta_{y}: a_{22} \theta_{y}^{\prime \prime}+a_{25}\left(v_{0}^{\prime \prime}+\theta_{x}^{\prime}\right)-a_{44}\left(u_{0}^{\prime}+\theta_{y}\right)-a_{34} \theta_{x}^{\prime}-\left(b_{5}+b_{15}\right) \ddot{\theta}_{y}=0
\end{gathered}
$$

Sınır koşulları $z=0$ 'da ankastre ve $z=L$ 'de serbest olmak üzere aşağıdaki şekilde verilmiştir:

$$
\begin{gathered}
u_{0}=0 ; v_{0}=0 ; \theta_{x}=0 ; \theta_{y}=0 \\
\delta u_{0}: a_{34} \theta_{x}^{\prime}+a_{44}\left(u_{0}^{\prime}+\theta_{y}\right)=0 \\
\delta v_{0}: a_{25} \theta_{y}^{\prime}+a_{55}\left(v_{0}^{\prime}+\theta_{x}\right)=0 \\
\delta \theta_{x}: a_{33} \theta_{x}^{\prime}+a_{34}\left(u_{0}^{\prime}+\theta_{y}\right)=\widetilde{M}_{x} \\
\delta \theta_{y}: a_{22} \theta_{y}^{\prime}+a_{25}\left(v_{0}^{\prime}+\theta_{x}\right)=\widetilde{M}_{y}
\end{gathered}
$$

Burada $a_{i j}$ ifadeleri katılık terimlerini belirtmektedir ve ifadeleri Eken ve Kaya (2015) tarafından ayrıntılı olarak gösterilmiştir. Genişletişmiş Galerkin metodu kullanılarak, uygun polinomların seçilmesi ile hareket denklemleri aşağıdaki gibi ayrıklaştılabilir:

$$
\begin{aligned}
& u_{0}(z, t)=N_{u}^{T}(z) q_{u}(t) \\
& v_{0}(z, t)=N_{v}^{T}(z) q_{v}(t) \\
& \theta_{x}(z, t)=N_{x}^{T}(z) q_{x}(t) \\
& \theta_{y}(z, t)=N_{y}^{T}(z) q_{y}(t)
\end{aligned}
$$

Burada deneme ya da şekil fonksiyonları olarak bilinen $N_{u}, N_{v}, N_{x}$ ve $N_{y}$ terimleri sadece geometrik sınır koşullarını sağlayacak şekilde seçilirken, $q_{u}, q_{v}, q_{x}$ ve $q_{y}$ genelleştirilmiş koordinat vektörlerini belirtmektedir. Denklem 47-50'de verilen ifadelerin Denklem 38-41'de yerine koyulup, uygun şekil fonksiyonları ile çarpıldıktan sonra kanat boyunca integrasyonları sonucu serbest titreşim problemi elde edilir.

$$
\mathbf{M} \ddot{q}(t)+\mathbf{K q}(t)=\mathbf{0}
$$

Burada $\mathbf{M}$ ve $\mathbf{K}$ kütle ve katılık matrislerini ifade etmekdir. Kütle ve katılık matrislerinin hesabı yapılırken, piezoelektrik malzemeler ve gömülü oldukları ana kompozit yapı birlikte hesaba katılmalıdır. Buna göre, uygulanan kontrol yasasına bağlı olarak, uyarlanabilir kanatlar için ayrıklaştııılmış virtüel iş Song ve arkadaşları (2001) tarafından ifade edilmiştir.

$$
\boldsymbol{\delta} \boldsymbol{J}=-\delta_{p} \boldsymbol{q}^{T} \boldsymbol{K}_{v} \mathbf{K}_{\mathrm{C}} \boldsymbol{\delta} \boldsymbol{q}-\delta_{v} \dot{\boldsymbol{q}}^{T} K_{p} \mathbf{K}_{\mathrm{C}} \boldsymbol{\delta} \boldsymbol{q}
$$

Bu sayede kapalı kontrol için ayrıklaştırılmış sistem aşağıdaki hale gelmektedir: 


$$
\mathbf{M} \ddot{\boldsymbol{q}}(\boldsymbol{t})+\delta_{v} K_{v} \mathbf{K}_{\mathbf{C}} \dot{\boldsymbol{q}}(\boldsymbol{t})+\mathbf{K} \boldsymbol{q}(\boldsymbol{t})+\delta_{p} K_{p} \mathbf{K}_{\mathbf{C}} \boldsymbol{q}(\boldsymbol{t})=\mathbf{0}
$$

$\mathbf{K}_{\mathbf{C}}$ literatürde kontrol matrisi olarak tanımlanmış olup uygulanan kontrol yasasına göre ayrıklaştırılmış hareket denklemlerine katkıda bulunur. Denklem 53'te de görüldüğ̈̈ üzere, iki ek terim $\delta_{P}$ ve $\delta_{V}$ hareket denklemlerine ilave edilmiştir ve sirasıyla oransal geri besleme kontrol yasası ile hız geri besleme kontrol yasalarının kullanımını ifade etmektedir (Librescu ve Song, 2005). Bu terimler kullanılan kontrol yasasına göre 1 veya 0 değerini alarak ayrıklaştırılmış hareket denklemlerini modifiye ederler. Oransal geri besleme kontrol yasasının kullanıldığı durumda $\delta_{P} 1$ değerini alırken $\delta_{V} 0$ değerini almaktadır. Hız geri besleme kontrol yasasının uygulandığı durumda ise tam tersi geçerlidir. Kontrol matrisi Song ve arkadaşları (2001) ve Librescu ve Song (2005) tarafindan aşağıdaki şekilde tanımlanmıştır:

$$
\mathbf{K}_{\mathrm{C}}=\left[\begin{array}{cccc}
\mathbf{0} & \mathbf{0} & \mathbf{0} & \mathbf{0} \\
\mathbf{0} & \mathbf{0} & \mathbf{0} & \mathbf{0} \\
\mathbf{0} & \mathbf{0} & C_{11} \boldsymbol{N}_{x}(L) \boldsymbol{N}_{x}^{T}(L) & \mathbf{0} \\
\mathbf{0} & \mathbf{0} & \mathbf{0} & C_{22} \boldsymbol{N}_{y}(L) \boldsymbol{N}_{y}^{T}(L)
\end{array}\right]
$$

Burada $C_{11}$ ve $C_{22}$ terimleri kullanılan piezoelektrik malzemenin elastik katsayılarını ifade etmektedir. Ayrıklaştıılmış hareket denklemlerinin durum-uzay temsiline geçirilmesi ile birlikte çözüm eldesi yapılabilir. Durum-uzay temsili aşağıdaki şekilde ifade edilebilir:

$$
\dot{\mathbf{x}}(t)=\mathbf{A x}(t)
$$

A matrisi aşağıdaki gibi verilmiştir:

$$
\mathbf{A}=\left[\begin{array}{cc}
\mathbf{0} & \mathbf{I} \\
-\mathbf{M}^{-1} \widehat{\mathbf{K}} & -\delta_{v} K_{v} \mathbf{M}^{-1} \mathbf{K}_{C}
\end{array}\right]
$$

Burada $\mathbf{0}$ ve I sırasıyla sıfır ve birim matrisleri belirtmektedir. $\widehat{\mathbf{K}}$ matrisi ise aşağıdaki şekildedir:

$$
\widehat{\mathbf{K}}=\mathbf{K}+\delta_{p} K_{p} \mathbf{K}_{\mathbf{C}}
$$

Serbest titreşim problemleri için, Denklem 55'in çözümü aşağıdaki şekilde ifade edilebilir:

$$
\mathbf{x}(\boldsymbol{t})=\boldsymbol{X} e^{\lambda t}
$$

Bu durumda serbest titreşim problemi bir özdeğer problemine dönüşecektir.

$$
A \mathbf{X}=\lambda \mathbf{X}
$$

Hız geri besleme kontrol yasasının uygulandığı durumda, $K_{v} \neq 0$, özdeğerler kompleks sayılar olacaktır. A matrisinden de açıkça görüldüğü üzere, yapısal ya da diğer sönümleme mekanizmaları devrede olmadığı zaman hız geri besleme kontrol yasası titreşim sönümlemesi için tek seçenek olarak gözükmektedir. Özdeğerler ve yapısal sönümleme faktörü ifadeleri aşağıdaki şekilde verilmiştir.

$$
\begin{gathered}
\lambda_{r=} \eta_{r} \pm i \omega_{d} r \\
\xi_{r}=\frac{-\eta_{r}}{\sqrt{\eta_{r}^{2}+\omega_{d}^{2} r}}
\end{gathered}
$$

Özdeğerler $\lambda$ ile ifade edilmekteyken, yapının doğal frekansları $\omega=\sqrt{\lambda}$ ile elde edilecektir. Kütle ve katılık matrisleri ile genelleştirilmiş koordinat vektörleri Eken ve Kaya (2015) tarafindan detaylıca anlatılmıştır.

\section{Araştırma Sonuçları ve Tartışma}

Yapılmış olan bu çalışmada, Şekil 1'de gösterilen elmas kesite sahip uyarlanabilir bir ince cidarlı kompozit kiriş sayısal simülasyonlar için incelenmiştir. Kullanılan kompozit (grafit-epoksi) ve piezoelektrik malzeme (PZT-4 seramikleri) özellikleri Tablo 1'de verilmiştir. Kapalı devre kontrol sistemi elde etmek için, piezoeyleyici ve algılayıcılar kompozit yapının içerisine çiftler olarak gömülmüş ve bütün kiriş boyunca yayılmıştır. İki farklı kontrol yasası ele alınmış ve bu kontrol yasaları için elyaf açısı $(\theta)$, açıklık oranı (AR) ve kalınlık 
oranı (t/b) parametrelerinin doğal frekanslar üzerinde etkisi incelenmiş ve tartışılmıştır. Elyaf açıları 0 ile 90 derece arasında 15 'er derecelik açılarla değiştirilirken, açıklık oranları genişlik sabit tutularak 10 ile 30 arasında değiştirilmiş ve kalınlık oranları ise yine genişlik sabit tutularak 0.04 ile 0.12 arasında değiştirilmiştir. Bu çalışmada kullanılan modelin doğruluğunu test etmek amacıyla, piezoelektrik etkilerin dahil edilmediği çalışmamızın sonuçları (Yildiz vd., 2014) literatürde verilmiş olan sonuçlar (Librescu ve Song, 2005) ile karşılaştırılmış ve modelimizin doğruluğu kanıtlanmıştır.

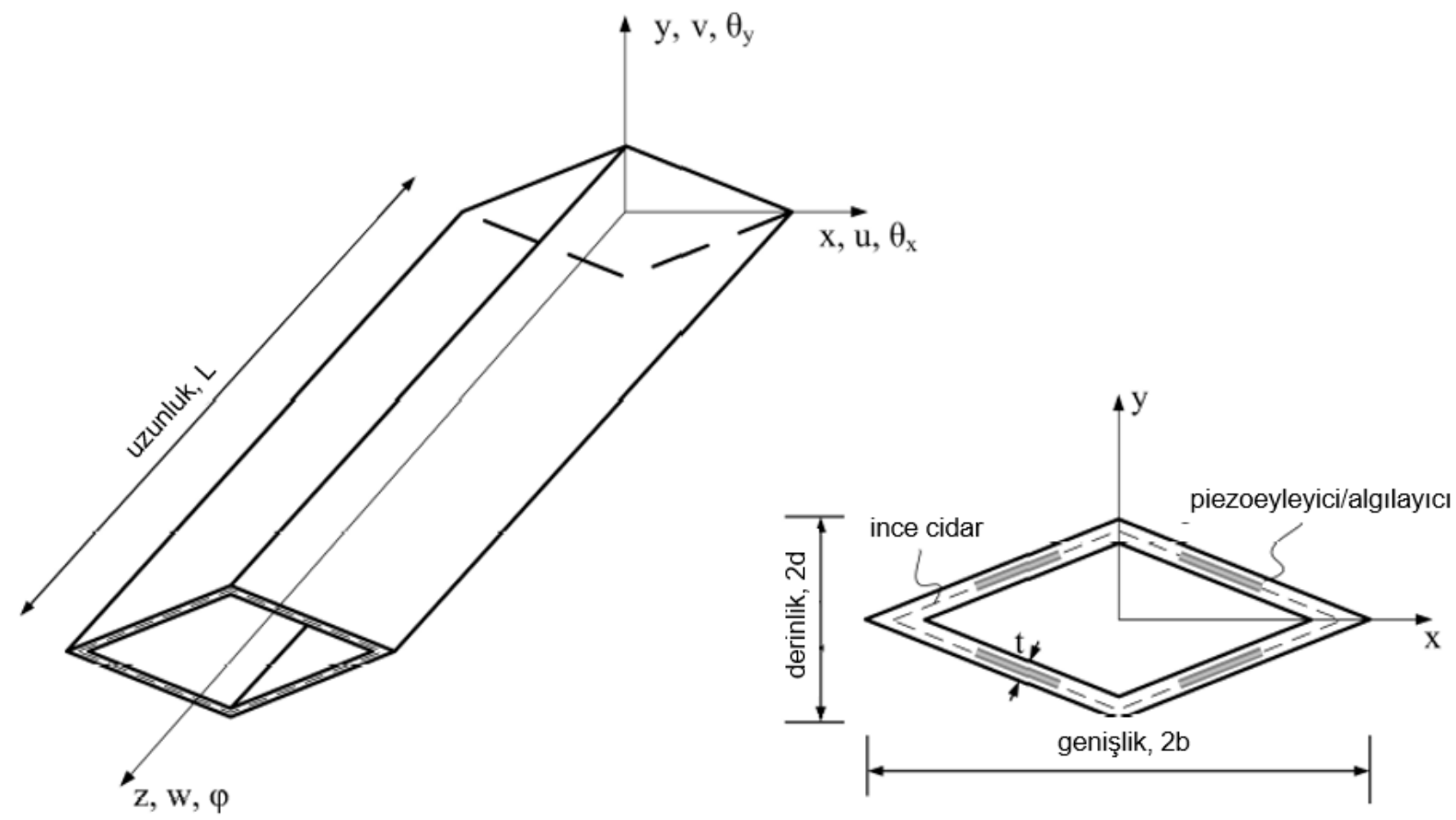

Şekil 1 Elmas kesitli kanat geometrisi ve kesit alanı

Tablo 1 Malzeme özellikleri ve kanadın geometrik bilgisi

\begin{tabular}{|c|c|c|c|}
\hline \multicolumn{2}{|c|}{ Grafit-Epoksi } & \multicolumn{2}{|c|}{ PZT-4 } \\
\hline$E_{11}$ & $206.75 \mathrm{GPa}$ & $C_{11}=C_{22}$ & $139 \mathrm{GPa}$ \\
\hline$E_{22}=E_{33}$ & $5.17 \mathrm{GPa}$ & $C_{12}$ & $77.77 \mathrm{GPa}$ \\
\hline$G_{12}$ & $3.10 \mathrm{GPa}$ & $C_{13}$ & $74.30 \mathrm{GPa}$ \\
\hline$G_{13}=G_{23}$ & $2.55 \mathrm{GPa}$ & $C_{33}$ & $115 \mathrm{GPa}$ \\
\hline$V_{21}=V_{31}$ & 0.00625 & $C_{44}$ & $25.59 \mathrm{GPa}$ \\
\hline$V_{32}$ & 0.25 & $\rho_{p}$ & $7498 \mathrm{~kg} / \mathrm{m}^{3}$ \\
\hline$\rho$ & $1528.15 \mathrm{~kg} / \mathrm{m}^{3}$ & $e_{31}$ & $-5.202 \mathrm{~N} / \mathrm{Vm}$ \\
\hline & & $e_{33}$ & $15.101 \mathrm{~N} / \mathrm{Vm}$ \\
\hline \multicolumn{4}{|c|}{ Geometri } \\
\hline \multicolumn{2}{|c|}{ Genişlik, 2b } & \multicolumn{2}{|c|}{$0.0254 \mathrm{~m}$} \\
\hline \multicolumn{2}{|c|}{ Derinlik, 2d } & \multicolumn{2}{|c|}{$0.00508 \mathrm{~m}$} \\
\hline \multicolumn{2}{|c|}{ Kalınlık, h } & \multicolumn{2}{|c|}{$0.001016 \mathrm{~m}$} \\
\hline \multicolumn{2}{|c|}{ Uzunluk, L } & \multicolumn{2}{|c|}{$0.254 \mathrm{~m}$} \\
\hline \multicolumn{2}{|c|}{ Katman sayısı } & \multicolumn{2}{|c|}{6} \\
\hline
\end{tabular}

\subsection{Oransal Geri Besleme Kontrol Yasası}

Yapılan bu çalışmada ilk olarak sisteme oransal geri besleme kontrol yasası uygulanmış ve elyaf açısı, açıklık oranı ve kalınlık oranı yapının doğal frekansları üzerindeki etkisi artan oransal geri besleme kazancı altında incelenmiştir. Bu sonuçlar sırasıyla Şekil 2 , 3 ve 4 'te gösterilmiştir. 
Avrupa Bilim ve Teknoloji Dergisi

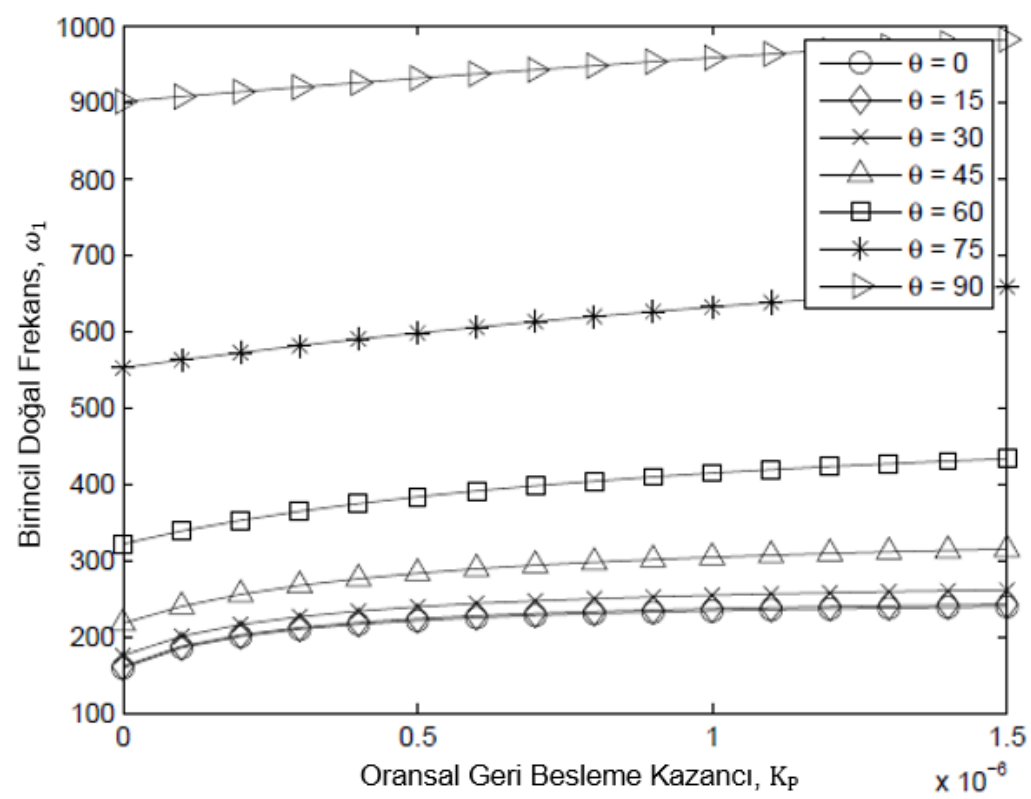

Şekil 2 Doğal frekansların seçilmiş olan elyaf açıları için oransal geri besleme kazancı ile değişimi

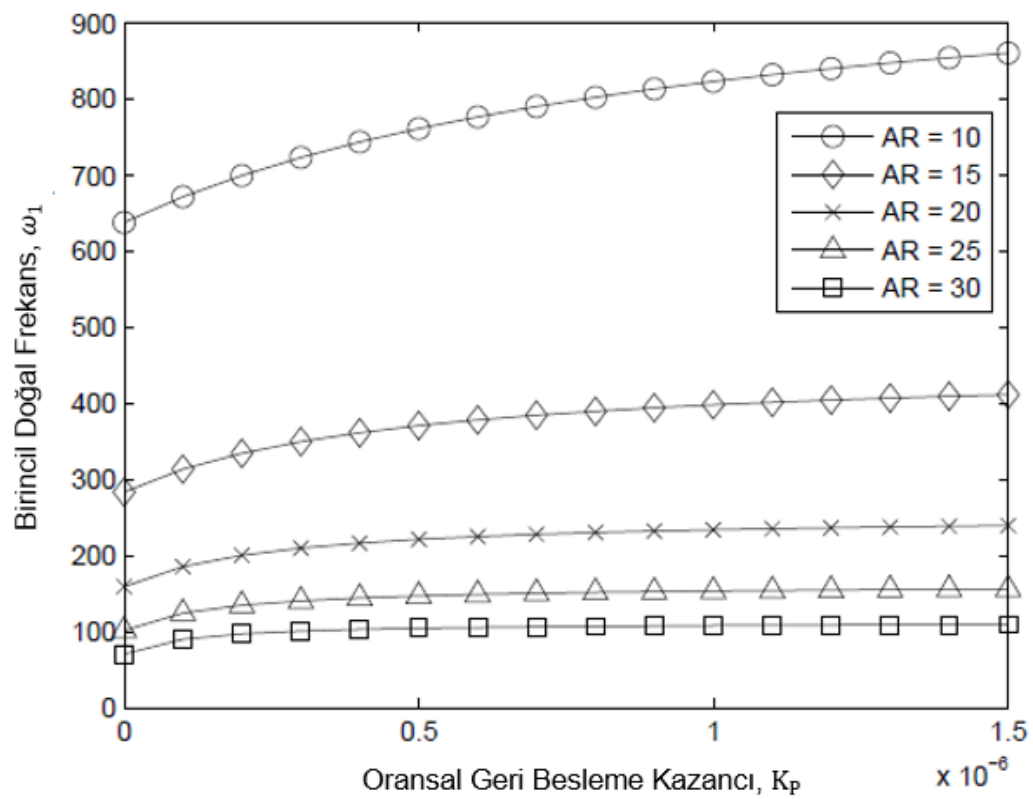

Şekil 3 Doğal frekansların seçilmiş olan açıklık oranları için oransal geri besleme kazancı ile değişimi 


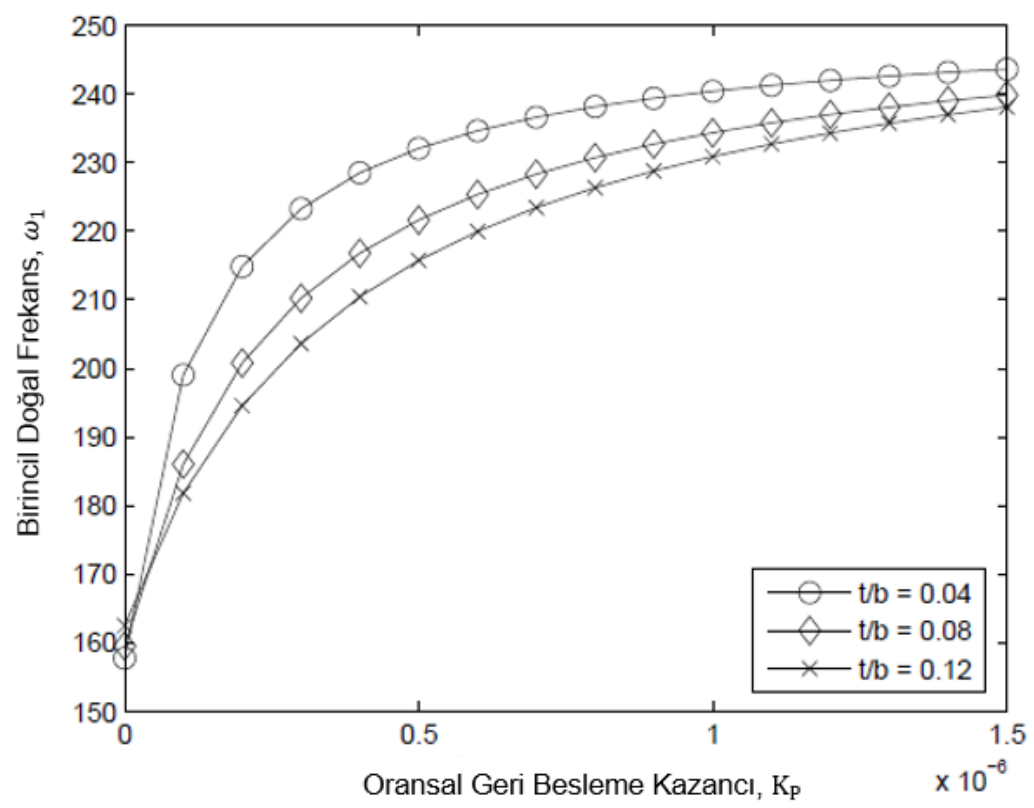

Şekil 4 Doğal frekansların seçilmiş kalınlık oranları için oransal geri besleme kazancı ile değisşimi

Şekil 2'den görüldüğü kadarıyla doğal frekansların artan oransal geri besleme kazancı ile statik gibi (quasi-static) davranış gösterdiği ortaya çıkmıştır. Her ne kadar doğal frekanslardaki değişim oransal geri besleme kontrol yasası ile oldukça az gözükse de en yüksek kontol edilebilirlik düşük elyaf açıları ile elde edilmiştir. Şekil 3’te gösterilmiş olan sonuçlara göre kanadın açıklık oranı arttığında doğal frekanslarda azalma gözlenmiş ve aynı zamanda kontrol edilebilirlik ortadan kalkmıştır. Kalınlık oranının değişimi ile doğal frekanslardaki değişim Şekil 4 'te gösterilmiştir. Kalınlık oranının azalması ile daha ince kirişler elde edilmiş ve daha yüksek kontrol edilebilirlik ortaya çıkmıştır. Böylece kontol kazancının değişimi ile birlikte doğal frekansların yükseltilmesi daha efektif bir şekilde sağlanabilecektir.

\subsection{Hız Geri Besleme Kontrol Yasası}

İkinci kontrol yasası olarak aynı elmas kesitli kanat üzerine hız geri besleme kontrol yasası uygulanmış ve sonuçlar benzer bir şekilde verilmiştir. Öncelikli olarak elyaf açısının doğal frekanslar üzerindeki etkisi artan hız geri besleme kazancı altında incelenmiştir. Şekil 5'te görüldüğü üzere, elyaf açısındaki artış ile birlikte doğal frekanslarda artış gözlemlenmiştir. Oransal geri besleme kontrol yasasından farklı olarak, kontrol edilebilirlik yüksek elyaf açılarında artan kontol kazancı çok yüksek olarak elde edilmiştir. Ayrıca yüksek elyaf açıları için doğal frekanslarda ani değişimler görülmüş ve bu değişimler için gerekli olan kontol kazancının elyaf açısın artması ile yükseldiği ortaya konmuştur.

Şekil 6'de kirişin açıklık oranının doğal frekanslar üzerindeki etkisi gösterilmiştir. Elde edilen sonuçlar oransa geri besleme kontrol yasasına benzer davranış ortaya koymaktadır. Artan açıklık oranı ile doğal frekanslarda azalma gözlenmiş ve kontrol edilebilirlikte düşüş yaşanmıştır. Son olarak Şekil 7'de kalınlık oranının değişimi ile birlikte doğal frekanslardaki değişim incelenmiştir. Elde edilen sonuçların ilginç bir davranış sergileyi gözlemlenmiştir. En kalın kiriş herhangi bir kontrolün olmadığı durumda en düşük doğal frekansı gösterirken, uygulanan hız kontrol kazancı ile birlikte, sahip olduğu kontrol edilebilirlik sayesinde, doğal frekansta çok büyük değişimler yaşanmış ve daha ince kirişlerin doğal frekanslarından daha yüksek doğal frekans elde edilmiştir. 


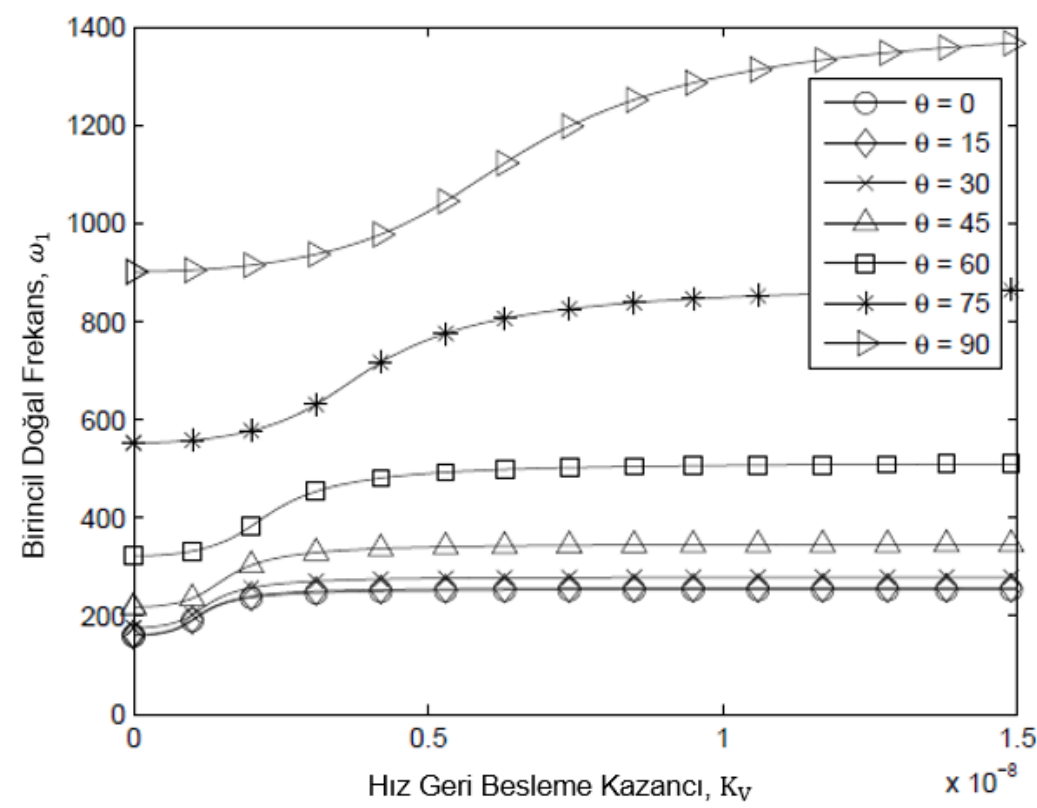

Şekil 5 Doğal frekansların seçilmiş olan elyaf açıları için hız geri besleme kazancı ile değişimi

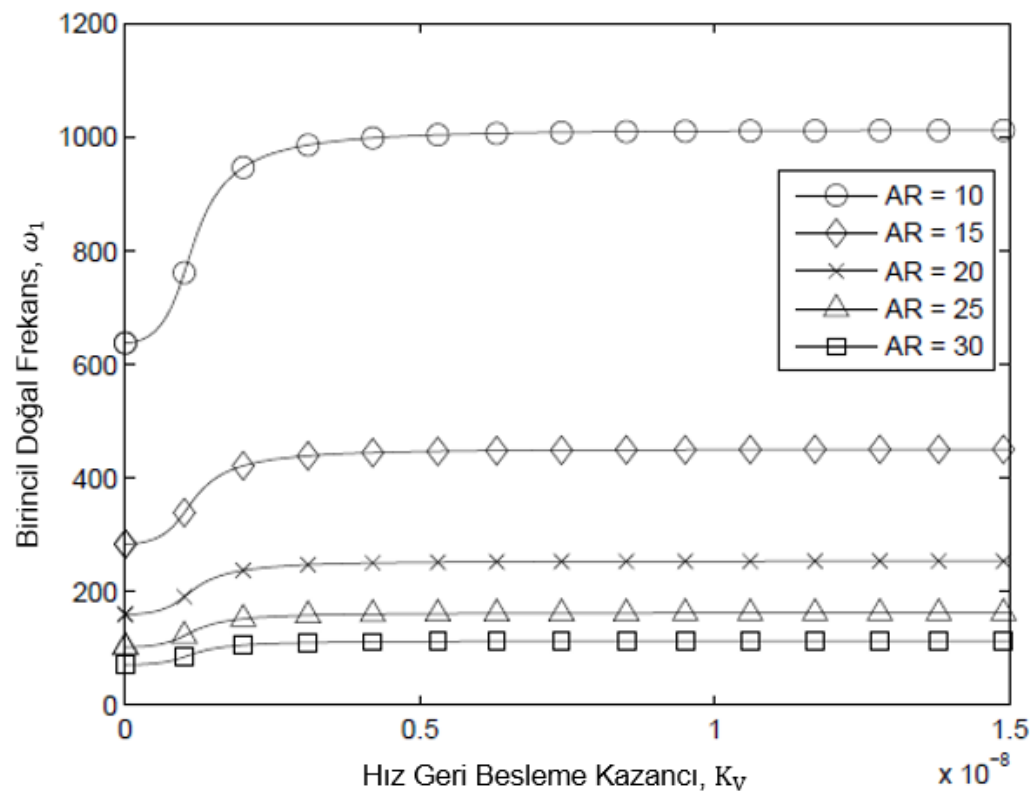

Şekil 6 Doğal frekansların seçilmişs olan açıklık oranları için hız geri besleme kazancı ile değişsimi 


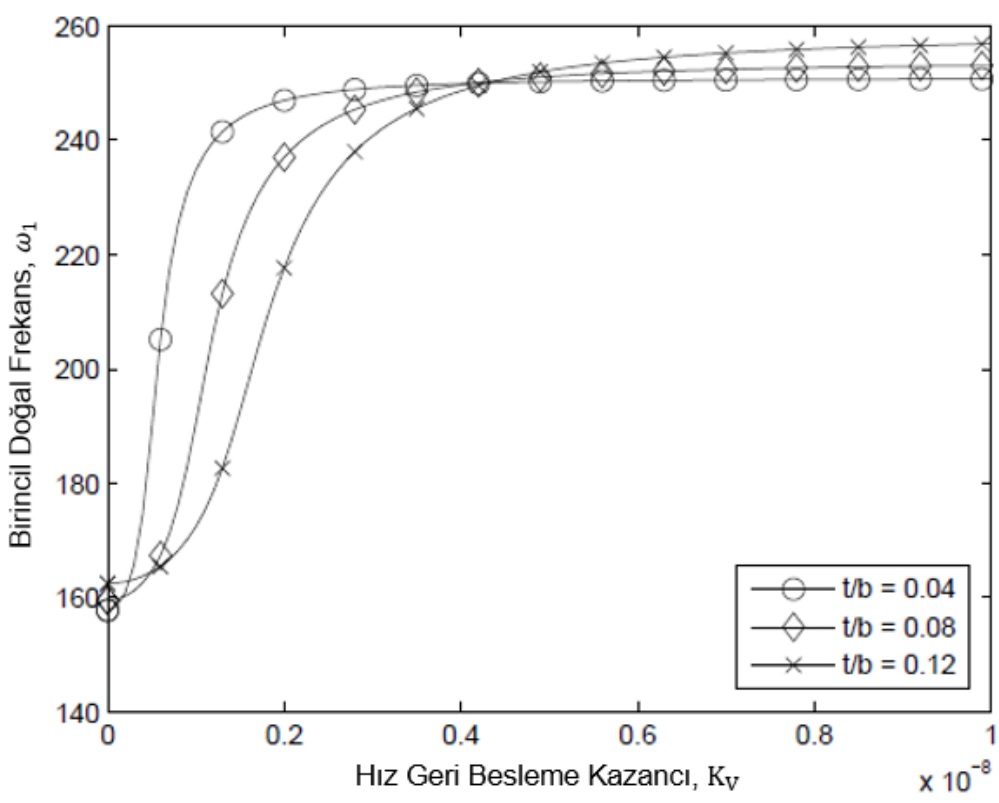

Şekil 7 Doğal frekansların seçilmiş olan kalınlık oranları için hız geri besleme kazancı ile değişmi

Son olarak ise sönümleme faktörlerinin artan hız kontrol kazancı ile değişimi seçili elyaf açıları için incelenmiștir. Şekil 8'de verilen sonuçlara göre sönümleme faktörleri belirli bir maksimum değere ulaşmakta ve daha sonrasında ani bir şekilde düşmektedir. Beklenen davranışın aksine, sönümleme faktörleri artan kontrol kazancı ile birlikte artmaya devam etmemektedir. Elde edilen bu sonuç aynı zamanda Tzou (1993) tarafından da rapor edilmiştir. Arttırılan hız kontrol kazancı ile birlikte sönümleme faktörlerinde artış sağlanmış ancak daha sonrasında ciddi düşüşler gözlemlenmiştir.

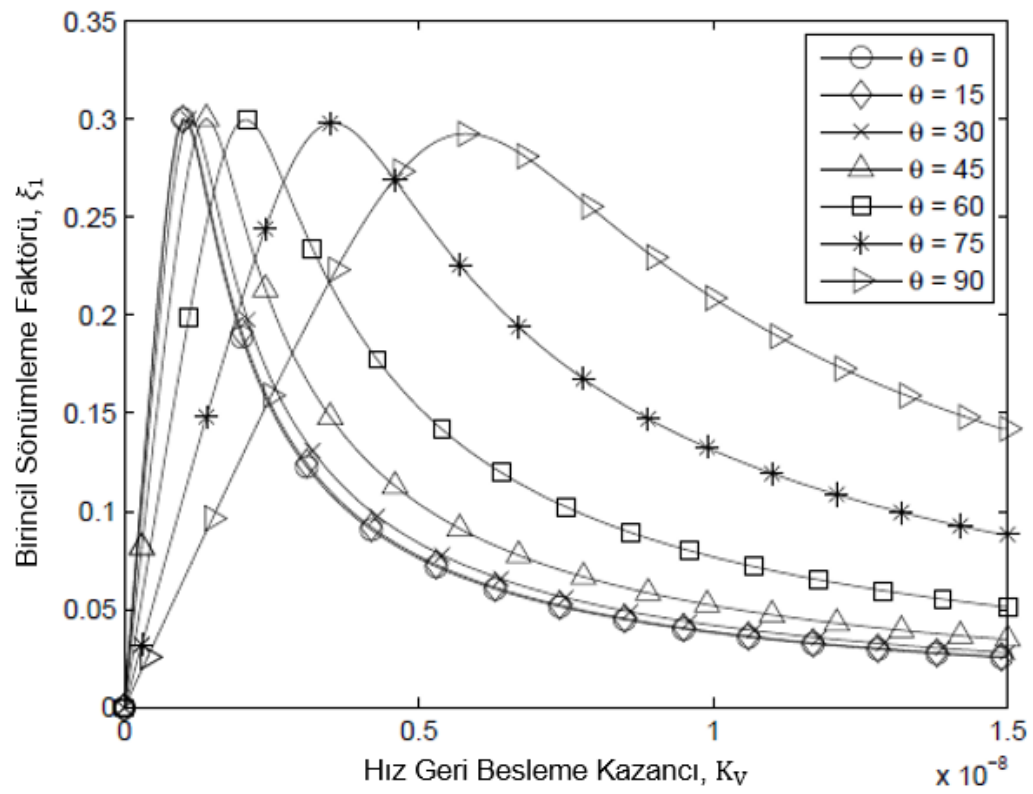

Şekil 8 Sönümleme faktörünün seçilmiş olan elyaf açıları için hız geri besleme kazancı ile değisşimi

\section{Sonuç}

Yapılmış olan bu çalışmada bir uçak kanadının piezoelektrik malzemeler yardımıyla aktif titreşim kontrolü sınır moment kontrolü yöntemi ile çalışılmış̧ır. Uçak kanadı ince cidarlı kompozit kiriş olarak modellenmiş ve anti-simetrik konfigürasyonda eğilme-eğilme bağlaşımını modelleyen hareket denklemlerinden yola çıkılarak, çözüm yöntemi anlatılmıştır. İki farklı geri besleme kontrol yasası ele alınmıştır ve bu kontrol yasalarının etkisi altında uçak kanadının dinamik davranışı incelenmiş̧ir. Elyaf açısı, açılık oranı ve kalınlık oranı gibi parametrelerin değişiminin doğal frekanslar üzerindeki etkisi elde edilmiş ve kontrol yasalarının kıyaslaması yapılmıştır.

Elde edilen sonuçlar ışı̆̆ında kapalı devre aktif titreşim kontrol yöntemlerinin hava-uzay yapılarının tasarımında oynayabileceği önemli rol ortaya konulmuştur. Sınır moment kontrolü ile birlikte doğal frekanslarda artışlar sağlanmış, dolayısıyla çalışılan uçak kanadının dinamik performansının potansiyel olarak geliştirilebileceğinin sinyaller verilmiştir. Aynı zaman uygulanacak kapalı kontrol sistemleri sayesinde, dinamik kararsızlıkların da önüne geçilebileği düşünülmektedir. Her ne kadar incelenen iki kontrol yasası da bu bağlamda iyileştirmeler sağlayabilecek potansiyelde olsalar da hız geri besleme kontrol yasası ilave yapısal sönümleme yeteneği kazandırabileceğinden, oransal geri besleme kontrol yasasına göre daha elverişli bulunmuştur. 


\section{Kaynakça}

Bailey, T., \& Hubbard Jr, J. E. (1985). Distributed piezoelectric-polymer active vibration control of a cantilever beam. Journal of Guidance, Control, and Dynamics, 8(5), 605-611.

Crawley, E. F., \& De Luis, J. (1987). Use of piezoelectric actuators as elements of intelligent structures. AIAA journal, 25(10), 13731385.

Eken, S., \& Kaya, M. O. (2015). Flexural-torsional coupled vibration of anisotropic thin-walled beams with biconvex cross-section. Thin-Walled Structures, 94, 372-383.

Ghosh, K., \& Batra, R. C. (1995). Shape control of plates using piezoceramic elements. AIAA Journal, 33(7), $1354-1357$.

Han, J. H., Rew, K. H., \& Lee, I. (1997). An experimental study of active vibration control of composite structures with a piezo-ceramic actuator and a piezo-film sensor. Smart Materials and Structures, 6(5), 549.

Librescu, L., Song, O., \& Rogers, C. A. (1993). Adaptive vibrational behavior of cantilevered structures modeled as composite thinwalled beams. International Journal of Engineering Science, 31(5), 775-792.

Librescu, L., Meirovitch, L., \& Song, O. (1996). Integrated structural tailoring and control using adaptive materials for advanced aircraft wings. Journal of Aircraft, 33(1), 203-213.

Librescu, L., Meirovitch, L., \& Na, S. S. (1997). Control of cantilever vibration via structural tailoring and adaptive materials. AIAA journal, 35(8), 1309-1315.

Librescu, L., \& Song, O. (2005). Thin-walled composite beams: theory and application (Vol. 131). Springer Science \& Business Media.

Meirovitch, L. (1997). Principles and techniques of vibrations (Vol. 1). New Jersey: Prentice Hall.

Mitchell, J. A., \& Reddy, J. N. (1995). A refined hybrid plate theory for composite laminates with piezoelectric laminae. International Journal of Solids and Structures, 32(16), 2345-2367.

$\mathrm{Na}$, S. (1997). Control of dynamic response of thin-walled composite beams using structural tailoring and piezoelectric actuation (Doctoral dissertation, Virginia Tech).

Na, S., \& Librescu, L. (1998). Oscillation control of cantilevers via smart materials technology and optimal feedback control: actuator location and power consumption issues. Smart Materials and Structures, 7(6), 833.

Na, S., \& Librescu, L. (2000a). Dynamic response of adaptive cantilevers carrying external stores and subjected to blast loading. Journal of Sound and Vibration, 231(4), 1039-1055.

Na, S., \& Librescu, L. (2000b). Optimal vibration control of thin-walled anisotropic cantilevers exposed to blast loadings. Journal of Guidance, Control, and Dynamics, 23(3), 491-500.

Qin, Z. (2001). Vibration and Aeroelasticity of Advanced Aircraft Wings Modeled as Thin-Walled Beams--Dynamics, Stability and Control (Doctoral dissertation, Virginia Tech).

Wang, B. T., \& Rogers, C. A. (1991). Laminate plate theory for spatially distributed induced strain actuators. Journal of Composite Materials, 25(4), 433-452.

Song, O., Kim, J. B., \& Librescu, L. (2001). Synergistic implications of tailoring and adaptive materials technology on vibration control of anisotropic thin-walled beams. International Journal of Engineering Science, 39(1), 71-94.

Tzou, H. (1993). Piezoelectric shells: Distributed sensing and control of continua.

Yildiz, K., Eken, S., \& Kaya, M. O. (2014, November). Active Vibration Control of Aircraft Wings Modeled as Thin-Walled Composite Beams Using Piezoelectric Actuation. In ASME 2014 International Mechanical Engineering Congress and Exposition. American Society of Mechanical Engineers Digital Collection. 